\title{
A Review into the Acute Emergency Response of Operational Partnerships During the Rohingya Refugee Crisis in Cox's Bazar
}

\section{Claire Blackmore ( $\sim$ Claire.blackmore@nhs.net )}

World Health Organisation, Regional Office for South-East Asia

\section{Egmond Samir Evers}

World Health Organisation, Regional Office for South-East Asia

S M Asif Sazed

World Health Organisation, Cox's Bazar Emergency Sub-Office

Amrish Baidjoe

World Health Organisation, Regional Office for South-East Asia

Victor Del Rio Vilas

World Health Organisation, Regional Office for South-East Asia

Art Pesigan

World Health Organisation, Regional Office for South-East Asia

Roderico Ofrin

World Health Organisation, Regional Office for South-East Asia

\section{Research Article}

Keywords: humanitarian response, health emergencies, operational deployments, refugee setting, human resources for health

Posted Date: December 20th, 2021

DOI: https://doi.org/10.21203/rs.3.rs-1126664/v1

License: (c) (1) This work is licensed under a Creative Commons Attribution 4.0 International License. Read Full License 


\section{Abstract}

Background: The unprecedented influx of Rohingya refugees into Cox's Bazar, Bangladesh, in 2017 led to a humanitarian emergency requiring large numbers of humanitarian workers to be deployed to the region. The World Health Organization (WHO) contributed to this effort through several well-established deployment mechanisms: the Global Outbreak Alert and Response Network (GOARN) and the Standby Partnerships (SBP). The aim of the study was to capture the views and experiences of those humanitarian workers deployed by WHO through operational partnerships between December 2017 and February 2019.

Methods: A mixed methods design was used. A desktop review was conducted to describe the demographics of the humanitarian workers deployed to Cox's Bazar and the work that was undertaken. Interviews were conducted with a subset of the respondents to elicit their views relating to their roles and contributions to the humanitarian response, challenges during their deployment and how the process could be improved. Thematic analysis was used to identify key themes.

Results: We identified sixty-five deployments during the study period. Respondents' previous experience ranged between 3 and 28 years (mean 9.7 years). The duration of deployment ranged from 8 to 278 days (mean 67 days) and there was a higher representation of workers from Western Pacific and European regions. Forty-one interviews were conducted with people who experienced all aspects of the deployment process. Key themes elicited from interviews related to staffing, the deployment process, the office environment and capacity building. Various issues raised have since been addressed, including the establishment of a sub-office structure, introduction of online training prior to deployment, and a staff wellbeing committee.

Conclusions: This study identified successes and areas for improvement for deployments during emergencies. The themes and subthemes elicited can be used to inform policy and practice changes, as well as the development of performance indicators. Common findings between this study and previous literature indicate the pivotal role of staff deployments through partnership agreements during health emergency response operations and a need for continuous improvements of processes to ensure maximum effectiveness.

\section{Background}

In 2017, over 700,000 Rohingya refugees crossed from Myanmar into Bangladesh joining refugees from previous waves of displacement (1-3) to form the largest refugee camp in the world, currently hosting over 850,000 refugees, and straining the resources of one of Bangladesh's poorest districts (4).

The Rohingya refugees faced considerable public health challenges, including severe and acute (mental) trauma, housing in overcrowded camps, poor water sanitation and hygiene (WASH) conditions, poor nutritional status (5), low vaccination coverage (6) and others. 
The number of refugees rapidly overwhelmed the limited available capacity of local communities and health systems, and additional health service capacity was required. The Government of Bangladesh requested international assistance, and the World Health Organization (WHO) took on the leadership of the Health Sector Coordination in support of the Government on 1st October 2017. In an emergency of this scale, it was necessary for WHO to collaborate with operational partners in line with the Regional Framework on operational partnerships for emergency response to achieve a timely, coordinated, effective and efficient emergency response (7). Standby Partnerships (SBPs) and the Global Outbreak Alert and Response Network (GOARN) contributed significantly to the staffing of WHO operations in Cox's Bazar.

Standby Partnerships are bilateral agreements between organizations and UN agencies, with partners providing support to UN agencies responding to humanitarian emergencies through the secondment of gratis personnel. Each Standby Partner maintains its own roster of humanitarian experts (8). These personnel have been pre-identified and can be rapidly mobilized.

GOARN is a global partnership which can deploy personnel with technical and operational skillsets to support public health emergency response (9). The GOARN secretariat and operational support team are based in WHO Headquarters in Geneva, Switzerland, and at several WHO regional offices. Partners include networks of academic institutions, laboratories and regional technical networks, medical and surveillance initiatives, United Nations agencies, international humanitarian non-governmental organizations and national public health institutions.

\section{Previous research into deployments}

Humanitarian emergency response globally involves the deployment of large numbers of staff, often at significant financial cost. Research is needed to guide organisations to undertake these deployments efficiently, while ensuring the thorough vetting and wellbeing of deployed staff.

Limited literature has been published on staff providing humanitarian assistance (10). Where it is available, the majority has been concentrated on the mental wellbeing of humanitarian workers, or focuses specifically on recruitment or the nature of the work. In addition to the operational constraints of research in humanitarian settings, workers deployed are often part of a transient workforce for which follow up can be challenging (11). To date, there has been little written on the process of their deployment, or the technical and operational aspects of the deployment process in the emergency response.

This article aims to describe the characteristics of deployees through operational partnerships mechanisms to the emergency response in Cox's Bazar, and to describe their deployment experiences. Results of this study can inform future changes in policy and practice related to deployments in humanitarian emergencies. 


\section{Methods}

A mixed methods approach was used: firstly, a desk review of deployments utilizing quantitative data was performed, followed by a qualitative study of interviews carried out with personnel involved in the response by operational partnerships in Cox's Bazar.

\section{Desk Review}

\section{Study design}

The desk review was a cross-sectional study from which descriptive statistics were derived to characterize the demographics and input of people deployed by GOARN and SBPs in Cox's Bazar.

\section{Study population}

The study population comprised of people deployed to Cox's Bazar through either GOARN or a Standby Partner as part of the emergency response to the Rohingya refugee crisis between December 2017 and February 2019.

\section{Data collection}

Data were extracted from a database held centrally at WHO Headquarters in Geneva, which included demographic details of deployees, dates of deployment, deployee role (job title) and incident management system function (wider technical area of working), releasing entity (operational partner) and grade. Previous experience and nationality were extracted from CVs submitted to WHO. Descriptions of contributions were extracted from technical reports and performance evaluation reports submitted by the workers at the end of their deployment.

\section{Interviews of Personnel}

\section{Study population}

Interviewees were selected persons with significant operational experience related to the deployment of operational partnership personnel. This included WHO staff from all levels of the organization (Headquarters, Regional Office, Country Office and Cox's Bazar Sub-Office), staff from operational partners who contributed to the deployment process, and deployees themselves.

\section{Study design}


A semi structured interview with a set of core questions was used, with flexibility to probe interviewees' answers further if needed. Interview questions used are included in Supplementary Materials.

\section{Data collection}

The interviews were conducted by an external consultant, unknown to the majority of interviewees. The setting of the interview varied: ideally interviews were conducted face to face, but where this was not practical, Skype or telephone interviews were used. All interviewees were assured that their responses would be anonymous and they could withdraw from the process at any point.

\section{Sampling technique}

Initially a purposive and stratified sampling frame was used, identifying twenty people representing each technical area or role of interest. This includes at least one representative from each area listed in Table 1 and their affiliation or location is listed in Table 2. As interviews progressed, a snowball sampling technique developed, with interviewees suggesting others to interview. Interviews were conducted until suggested interviewees had responded and saturation point was reached.

\section{Analysis}

Thematic analysis of the interviews was undertaken by the interviewer. The process of analysis followed the seven steps outlined by Braun and Clarke: transcription, reading and familiarization, coding, searching for themes, reviewing themes, defining and naming themes, and finalizing the analysis (12). Discussions were held by members of the authorship team $(C B, A P, A B)$ to clarify and triangulate themes and gain a fuller understanding of the interviewees' discourse.

\section{Ethical approval}

As this study is a service evaluation and no patients were involved, there was no requirement for ethical approval. Involvement in interviews was optional with no remuneration, and participants were informed of the aims of the study.

\section{Results}

\section{Desk review}

\section{Deployments of personnel}


There was a total of 65 deployments of personnel from operational partners to the WHO Cox's Bazar suboffice between December 2017 and February 2019: 43 deployments through GOARN and 22 through SBPs. Four people were deployed twice, two from GOARN and two from SBPs, giving a total of 61 individuals who were deployed during that period.

The majority of deployees fulfilled roles within the health expertise and operations function of the Incident Management System (IMS), as outlined in the WHO Emergency Response Framework (13), with the largest number of deployees fulfilling epidemiologist or surveillance officer roles. Specific job roles are included in Table 1.

Table 1

Job roles and related IMS (Incident Management System) function for staff deployed to Cox's Bazar December 2017 - February 2019

\section{Gender of deployees}

Of the 65 deployments, 32 were male and 33 were female. Two women and two men were deployed twice.

\section{Nationality of deployees}

Information on nationality was available for 63 of the 65 deployments. The highest number $(26$ deployees, 41.2\%) came from the EURO region, followed by Western Pacific region (14, 22.2\%) and PanAmerican region (11, 17.5\%). Six deployees came from countries within the Eastern Mediterranean region (9.5\%), five came from the African region (7.9\%) and one deployee came from within the South-East Asia region $(1.6 \%)$.

\section{Level of experience and education}

Deployees' relevant occupational experiences were not always directly linked to humanitarian or the public health sector, with some deployees having relevant experience from the private sector. The number of years of experience ranged from three to 28 (mean 9.7). This is shown in Figure 1. All deployees except one provided educational achievements on their $\mathrm{CV}$, with all being in possession of at least a Bachelor's degree. Eight were medically qualified and ten had PhDs.

\section{Duration of deployment}

The length of deployment ranged from eight days to 278 days, shown in Figure 2. The mean length of deployment was 67 days, with GOARN deployments tending to be shorter (mean 40 days, range 8-91) and 


\begin{tabular}{|lll|}
\hline $\begin{array}{l}\text { Deployee IMS function } \\
\text { Health expertise and }\end{array}$ & Deployee role & $\begin{array}{l}\text { Number of deployments } \\
\text { op) }\end{array}$ \\
\hline & Case management officer & $3(4.6)$ \\
\hline & Fidemiologist & $18(27.7)$ \\
\hline & Health operations team lead & $4(6.2)$ \\
\hline Infection prevention and control & $1(1.5)$ \\
\hline Laboratory technical officer & $6(9.2)$ \\
\hline Public health officer & $2(3.1)$ \\
\hline Surveillance officer & $1(1.5)$ \\
\hline Leadership & Epidemiology team lead & $9(13.8)$ \\
\hline Mental health technical officer & $1(1.5)$ \\
\hline logistics & WASH officer & $1(1.5)$ \\
\hline & Communications officer & $4(6.2)$ \\
\hline & Resource mobilization officer & $3(4.6)$ \\
\hline & Health logistics officer & $1(1.5)$ \\
\hline
\end{tabular}

deployments through SBPs lasting longer (mean 119 days, range 23-278). The longest deployments were between March and August 2018. This is also reflected when looking at the number of deployees in the Cox's Bazar office at any given time (Figure 3). This peaked at 18 deployees in May and July 2018, then reduced gradually over time.

\section{Interviews of personnel}

Forty-one interviews were conducted with people involved in the deployments of personnel to Cox's Bazar. Their affiliation is shown in Table 2. 
Table 2

Location of interviewees

\begin{tabular}{|ll|}
\hline Group, by location & \multicolumn{1}{|c|}{$\begin{array}{c}\text { Number of } \\
\text { people }\end{array}$} \\
\hline $\begin{array}{l}\text { WHO Headquarters (Geneva, Switzerland) including GOARN and SBP } \\
\text { secretariats }\end{array}$ & 4 \\
\hline WHO South-East Asia Regional Office (New Delhi, India) & 7 \\
\hline WHO Bangladesh Country Office (Dhaka, Bangladesh) & 5 \\
\hline WHO Cox's Bazar Emergency Sub-Office (Cox's Bazar, Bangladesh) & 11 \\
\hline Deployees & 11 \\
& $($ SBP = 6, GOARN \\
\hline $\begin{array}{l}\text { SBPs: representatives from RedR Australia, Save the Children UK and Norwegian } \\
\text { Refugee Council }\end{array}$ & 3 \\
\hline SBP = Standby partner & \\
\hline
\end{tabular}

\section{Key themes}

Four key themes were elicited by thematic analysis of the interviews: "staffing", "deployment process", "office" and "capacity building". Within these four key themes, there are between two and four master themes, and several subthemes. These are shown in Table 3, with example quotes where interviewees suggested areas for development for each subtheme.

Table 3

Themes and subthemes identified from interviews with example quotes 


\begin{tabular}{|c|c|c|c|}
\hline Themes & $\begin{array}{l}\text { Master } \\
\text { themes }\end{array}$ & Subthemes & Example quotes \\
\hline \multirow[t]{15}{*}{ 1. Staffing } & \multirow[t]{5}{*}{$\begin{array}{l}\text { Team } \\
\text { structure }\end{array}$} & \multirow{3}{*}{$\begin{array}{l}\text { Incident } \\
\text { Management } \\
\text { Structure (IMS) }\end{array}$} & $\begin{array}{l}\text { "I did not feel it was a hierarchical } \\
\text { environment" }\end{array}$ \\
\hline & & & $\begin{array}{l}\text { "There are communication gaps within the } \\
\text { IMS, both horizontally and vertically" }\end{array}$ \\
\hline & & & $\begin{array}{l}\text { "Some people from partnerships are trained } \\
\text { and well versed in how WHO works and the } \\
\text { IMS" }\end{array}$ \\
\hline & & \multirow[t]{2}{*}{$\begin{array}{l}\text { Lead roles/team } \\
\text { positions }\end{array}$} & $\begin{array}{l}\text { "Leadership should be taken on by more } \\
\text { experienced deployees... if they are here long } \\
\text { enough" }\end{array}$ \\
\hline & & & $\begin{array}{l}\text { "It is better to give specific technical functions } \\
\text { to deployees, rather than lead positions or } \\
\text { management responsibility, as these roles } \\
\text { should be given to people who are present for } \\
\text { a longer period of time" }\end{array}$ \\
\hline & \multirow[t]{5}{*}{$\begin{array}{l}\text { Continuity } \\
\text { and } \\
\text { transition }\end{array}$} & \multirow[t]{3}{*}{$\begin{array}{l}\text { Duration of } \\
\text { deployment }\end{array}$} & $\begin{array}{l}\text { "There should be a minimum deployment } \\
\text { length of three months" "The same time is } \\
\text { spent on recruitment regardless of how long } \\
\text { they stay for, but the deliverables are very } \\
\text { different" }\end{array}$ \\
\hline & & & $\begin{array}{l}\text { "Those who contributed the most were those } \\
\text { who stayed for more than } 3 \text { months" }\end{array}$ \\
\hline & & & $\begin{array}{l}\text { "GOARN deployees are usually only for six } \\
\text { weeks, it would be good if this could be } \\
\text { extended" }\end{array}$ \\
\hline & & \multirow[t]{2}{*}{$\begin{array}{l}\text { Long-term staffing } \\
\text { plans }\end{array}$} & $\begin{array}{l}\text { "[Operational partnerships] should be used } \\
\text { [only] for deployment acutely" }\end{array}$ \\
\hline & & & $\begin{array}{l}\text { "We are moving towards recruiting longer term } \\
\text { staff, especially national staff. It would work } \\
\text { well if experienced deployees train the national } \\
\text { staff" }\end{array}$ \\
\hline & \multirow[t]{5}{*}{$\begin{array}{l}\text { Role of } \\
\text { deployees }\end{array}$} & \multirow[t]{4}{*}{$\begin{array}{l}\text { Terms of reference } \\
\text { (ToR) }\end{array}$} & $\begin{array}{l}\text { "Terms of reference need to be clear, both for } \\
\text { the receiving office and the deployee" }\end{array}$ \\
\hline & & & $\begin{array}{l}\text { "[unclear terms of reference] results in time not } \\
\text { being properly utilized" }\end{array}$ \\
\hline & & & "Terms of reference are very broad." \\
\hline & & & $\begin{array}{l}\text { "Contributions were greater when there was a } \\
\text { clear ToR with tasks that could be achieved in } \\
\text { the short space of time". }\end{array}$ \\
\hline & & Handover & $\begin{array}{l}\text { "Deployments should be staggered, with no } \\
\text { gaps" }\end{array}$ \\
\hline
\end{tabular}


"There should always be handovers"

Debriefing

"There should be a debriefing at the end of each deployment with a focal point from the organization"

"[Deployees] would find ways of handing over what was left and gave ideas on how it could be continued. They were mature, highly qualified, and concerned about handover"

$\begin{array}{ll}\text { Quality of } & \text { Performance } \\ \text { deployee } & \text { Evaluation Report } \\ \text { performance } & \text { (PER) }\end{array}$

"(The PER) is a very rigid evaluation structure [it] needs to include softer skills as well as the technical skills"

"An alternative to the PER could be a structured conversation"

"There is a need for an internal record that is distinct from the PER"

Roster

"A roster should be formed of individuals who have been to CXB and performed well, who we could ask to return"

Performance

review

"There should be a performance review process and an early evaluation"

"More feedback to deployees and deploying organizations is needed"

"An early assessment should be undertaken after two weeks"

\section{Preparation Preparation}

Deployment and arrival process

"Before initiating the deployment, you should receive letters, documents, and in good time... you need some internal documents and information"

"Deployees are usually informed about procedures for payment, leave etc by their deploying organization before leaving, so usually this is straightforward"

"Personnel deployed through GOARN have been briefed by GOARN, and there is a GOARN focal point"
SBP/GOARN deployment

"Deployments from GOARN/SBP were a lifesaver when we needed one"

“Deployments need to be more timely and reliable"

"GOARN personnel deployed were highly trained and deployed quickly"

Organizational structure
"Administrative questions at times must pass through 3-4 layers: field office administration, country-office, regional office and at times 
headquarters/global service center... which introduces a delay"

Training

"Training needs to be provided on the systems required"

"Different SBPs may offer different training, but all will receive a degree of mandatory training on operations, finance, security"

"In every position there are some particular training needs"

Orientation/briefing "It would be good to have a briefing for deployed personnel in a more structured way"

Recruitment

SBP/GOARN recruitment and selection
"Technical area experts should advise the GOARN/SBP partners to recruit deployees/technical experts with the required skillsets"

"Generally there has been appropriate matching between expertise, experience and local context"

"[An] advantage of using SBPs to deploy staff is that often staff know each other through being deployed with the same people previously"

Telephone call/Skype
"Although deployees are pre-selected through rosters, would still recommend having an interview or call on Skype before agreeing to deployment to discuss expectations"

3. Office Environment Office environment

"There were no set seating arrangements... members of the same team were at time distributed across different rooms"

"We now pay more attention to staff wellbeing"

"We have a staff wellbeing team trying to enhance team spirit and have everyone working as one"

"The SBPs brought diversity to the office they were from Kenya, Somalia, Afghanistan, Australia, Sudan"

Wider environment

"Individuals can have cultural sensitivity and be adaptable but it depends on the person and their experience"

"Generally, staff were experienced in working in different cultures and did not have trouble adjusting"

"There are less complex security issues than in other contexts where I have worked" 


\begin{tabular}{|c|c|c|c|}
\hline & \multirow[t]{3}{*}{$\begin{array}{l}\text { Policies and } \\
\text { procedures }\end{array}$} & $\begin{array}{l}\text { Rest and } \\
\text { recuperation (R\&R) }\end{array}$ & $\begin{array}{l}\text { "A clear [standard operating procedure] is } \\
\text { needed to ensure there is no confusion over } \\
\text { R\&R policies applicable to different contract } \\
\text { types and situations" }\end{array}$ \\
\hline & & Research & $\begin{array}{l}\text { "A mechanism is needed which makes it easy } \\
\text { to do research" }\end{array}$ \\
\hline & & Equipment/emails & $\begin{array}{l}\text { "My official email came only half-way through } \\
\text { my deployment. Some deployees were } \\
\text { temporarily using their personal email. Official } \\
\text { email accounts should be assigned as a } \\
\text { matter of routine" }\end{array}$ \\
\hline & \multirow[t]{2}{*}{ Support } & Supervision & "Supervision is key for less experienced staff" \\
\hline & & $\begin{array}{l}\text { Relationship with } \\
\text { SBP/ institution }\end{array}$ & $\begin{array}{l}\text { "There should be stronger communication } \\
\text { between [operational partners] and WHO at } \\
\text { field level to better meet needs" }\end{array}$ \\
\hline \multirow[t]{7}{*}{$\begin{array}{l}\text { 4. Capacity } \\
\text { building }\end{array}$} & \multirow[t]{2}{*}{$\begin{array}{l}\text { Sharing } \\
\text { experiences }\end{array}$} & Mentoring & $\begin{array}{l}\text { "[An operational partner] has a buddy system } \\
\text { where more junior staff are linked with seniors } \\
\text { who have 5-10 years' experience. This works } \\
\text { well” }\end{array}$ \\
\hline & & $\begin{array}{l}\text { Building } \\
\text { collaborations }\end{array}$ & $\begin{array}{l}\text { "No single institution has all the capacity and } \\
\text { so we need to use surge capacity from other } \\
\text { institutions" }\end{array}$ \\
\hline & \multirow[t]{5}{*}{$\begin{array}{l}\text { Increase of } \\
\text { SEARO } \\
\text { participation }\end{array}$} & \multirow[t]{2}{*}{ Pool of institutions } & $\begin{array}{l}\text { "We want to build capacity... institutions from } \\
\text { SE Asia are not yet as active/engaged as from } \\
\text { other regions" }\end{array}$ \\
\hline & & & $\begin{array}{l}\text { "The response from Western institutions is } \\
\text { disproportionate" }\end{array}$ \\
\hline & & \multirow[t]{3}{*}{ Regional focus } & $\begin{array}{l}\text { "It can be useful to use regional [operational } \\
\text { partners] due to culture and regional solidarity" }\end{array}$ \\
\hline & & & $\begin{array}{l}\text { "We should have a regionally focussed GOARN } \\
\text { mechanism for this WHO region. This way the } \\
\text { experience can be used in the region and we } \\
\text { build local capacity" }\end{array}$ \\
\hline & & & $\begin{array}{l}\text { "If people are from the region or have } \\
\text { experience in the region, they find it easier and } \\
\text { blend in well" }\end{array}$ \\
\hline
\end{tabular}

\section{Key theme 1: staffing}

Staffing was an issue highlighted by all interviewees. All those who were interviewed felt that staff deployed through partnership agreements played a pivotal role in the emergency response. 
The need for a clear team structure and reporting lines was emphasised, including communication of management decisions. Some interviewees believed the vertical structure of the Incident Management Structure (IMS) affected communication, at times preventing information from being shared.

Some interviewees recommended that team lead positions should be assigned to persons with considerable WHO experience and who would remain in the sub-office for longer, allowing for institutional memory and more effective functioning of the IMS. This also linked with continuity, with shorter deployments viewed as having some valuable contributions but at times being disruptive. However, it was recognised that the intensive workload, especially in early stages of the response, may not be sustainable for longer periods. Many interviewees called for a longer-term staffing plan as soon as it was clear that the emergency would be prolonged.

Clear terms of reference were raised by the majority of interviewees. Some deployees suggested for these to include a degree of flexibility and to be finalized on arrival with their supervisor to ensure that they are clear on the role requirements. Handover and debriefing were also seen as important elements, and that these processes should be formalised, ideally with both the inbound and outbound deployments overlapping on site.

Many persons interviewed expressed that the standardized performance evaluation report (PER) was not seen as sensitive enough to act as an adequate evaluation tool and had limited use in distinguishing successful deployments. Linked to this, an internal roster was seen by some as a way to positively distinguish deployees who had worked well in Cox's Bazar. Many suggested an early performance review, within the first two weeks of a deployment, in order to identify any potential problems and correct course as soon as possible.

\section{Key theme 2: deployment process}

There were requests for more information prior to deployment, both role-specific and general information about WHO systems and the WHO Emergencies programme. Staff from the Cox's Bazar sub-office commented that the timings of deployments would have the greatest added value if they coincide with greatest need and allow for handover from outgoing personnel. It was also felt that the process could be streamlined to reduce delays such as travel approvals and visas. Interviewees recognised that ideally everyone would be trained and familiar with WHO systems and procedures, but a minimum standard of deployees receiving training in relevant processes and IT systems would be beneficial. Alternatively, recruitment of more administrative support familiar with WHO systems could be considered. The importance of a thorough briefing was noted, specific to Cox's Bazar and including information on context, local culture and expectations.

More transparency was requested around recruitment of deployees, including selection of candidates. It was requested by those in the sub-office that they have a more active role in the recruitment process, and 
for a call prior to deployment between deployee and the receiving team to improve the preparation of both parties.

\section{Key theme 3: office}

The temporary nature of the Cox's Bazar sub-office premises, housed in hotel apartment blocks with several smaller rooms spread over different floors was raised. The layout was seen as contributing to fragmentation and detachment. It was raised that different office space might contribute to stronger coherence within and between teams.

Security restrictions and the cultural contextual challenges were raised, particularly by female deployees. Although considered important for staff wellbeing and productivity by all interviewed, applicable policies on leave and rest and recuperation were not clear for different contractual modalities and deployment types, resulting in perceived barriers in accessing this entitlement.

Some deployees noted that opportunities for valuable research and documentation which could improve public health practice for similar settings existed in Cox's Bazar, together with some enabling factors. At the same time, it was noted that some of these were missed due to operational challenges of conducting research in an emergency, as well as lengthy and unclear approval processes, questions around ownership of data and authorships. It was felt that responsibility for coordination of research efforts should be assigned within the IMS structure to a staff member based in the office for medium term.

Many deployees reported challenges with IT equipment and access, with delays in allocations of official laptops and email accounts leading to temporary use of personal devices, emails and cloud accounts. Concerns were raised around data storage, protection, and security. Establishing use of generic email addresses and function specific accounts was recommended to promote continuity, particularly for highturnover roles.

Operational supervision and support for issues both inside and outside of work within the office were key issues, especially for less experienced deployees, although this was seen to improve with the introduction of a staff wellbeing committee later in the emergency response. The request for support also included a stronger relationship between the operational partners and WHO at field level to permit more tailored identification of requirements, as well as to address concerns regarding deployees.

\section{Key theme 4: capacity building}

Interviewees recognised the importance of building local capacity. Suggestions for this included a roster for personnel with appropriate skillsets for different technical functions, particularly from within the region and increasing the number of local institutions and organizations with operational partnerships in place. This regional focus was seen as important to ensure that deployees have more familiarity with 
local customs and culture, and be better placed to quickly form relationships and build trust with the affected populations and local staff and administration.

Mentoring was mentioned several times in relation to the need for experienced staff, with suggestions for more experienced deployees to act as mentors to allow less experienced deployees to be deployed safely. Similarly, sharing experiences was linked to building collaborations between WHO and other institutions, as well as between the institutions themselves.

\section{Conclusions}

Analysis of staff demographics showed an equal gender split, and an overrepresentation of staff recruited from Europe and Western Pacific regions. Only one deployee was from the South-East Asia region, despite interviewees stating that local deployees may have adjusted better to the environment and would have had more local context-specific knowledge. Deployees generally brought considerable experience in humanitarian and public health work. In some situations, a compromise may be made between experience and offering opportunities to newer workers to develop capacities to ensure sufficient staffing numbers, including through early recruitment of local staff and subsequent capacity building.

There were different opinions on optimal duration of deployment. Some interviewees felt that six-week deployments were a sufficient period of time to offer meaningful contributions within the high-pressure environment of the emergency response, while others felt that contributions made during six-week deployments often did not weigh up to the disruptive effects of staff turn-over that were experienced and advised against shorter term deployments. The need for early performance reviews of deployees was recommended to improve effectiveness. Other issues relating to team organisation and structure, and the need for clear and specific terms of reference, had been identified by previous research (14-16). Likewise, requests for more information prior to deployment and a more streamlined deployment process have been found in prior studies $(11,17)$, whilst requests for more information on the selection and deployment of staff from operational partnerships was specific to this study.

Cultural challenges faced by deployees relating to the local context and the office environment were also not unique to this study. Working in a markedly different cultural context was often discussed in interviews and had been mentioned in the research carried out by Bjerneld et al. (11), and challenges relating to IT availability and access, data protection and continuity had been raised in other studies (18, 19). It was important for deployees to be working in the same office area as their team but this was not always possible in the Cox's Bazar sub-office due to the office layout. Physical office space arrangements in future emergencies could consider the likely size and structure of the teams necessary, and be planned to promote teamwork. This can also assist with mentoring, which was discussed in several interviews. There was a positive view of more experienced deployees building capacity of junior colleagues to share their skills and knowledge while responding to the emergency.

This study demonstrates feasibility of organizational operational research in a protracted emergency. It has identified themes (staffing, the deployment process, the office/base, and capacity building) which are 
seen as crucial to the quality and effectiveness of the deployment by both the people deployed and the receiving organisation. A number of these themes can lend themselves for policy and practice changes, as well as conversion into performance indicators for deployments for both the deploying and receiving organizations. Currently, only individual performance monitoring exists (in the form of performance reviews), but the development of wider monitoring and evaluation tools will help to assess the effectiveness of the deployments and improve their quality, for the individuals being deployed, their deploying organizations and the receiving organisation. The interviews conducted identified both strengths and areas for development in the themes identified, and it is hoped these can act as a trigger to conduct such monitoring and evaluation in future.

The common findings between this study and findings from literature indicate continued need to improve the process of deployment of humanitarian workers for effective response. This study provides the basis for further research into the operational and technical aspects of deployments during an emergency public health response. The aspects captured would constitute an important part of a comprehensive review of operations.

Since this exercise was conducted in 2019, various issues raised in this piece have been addressed, but are included here so other settings might learn from the Cox's Bazar experience and address any issues in a timely manner. Notably in 2018 , a staff wellbeing committee was established, which has since worked to flag staff wellbeing needs within the Cox's Bazar office, to formulate advice to management and to help address wellbeing challenges where possible. Following a broad operational review in late 2018, the establishment of a sub-office structure in 2019 , with delegations of authority to field level, clear administrative standard operating procedures and recruitment of administrative support staff with appropriate skillsets have been observed to have streamlined administration considerably overall. In late 2019, a move to medium-term oriented office space addressed some of the limitations flagged by deployees in the earlier office accommodation, which was perceived to limit team's functionality. A consultant was hired specifically to coordinate and further research efforts conducted in the duty station in 2019, and GOARN has initiated an online interactive training to raise awareness among those eligible to be deployed on the realities and challenges of working with GOARN in the field on an outbreak response mission. The development of a strategic plan for the health response, structured organizational workplans and mobilization of funding are some priorities to ensure staffing can be transferred from operational partners to organizational staff as early as possible.

\section{Limitations}

The study does not cover internal deployments within WHO, which were largely from the South-East Asia region, particularly the WHO country office in Bangladesh. It also does not cover Government deployments, including from the national FETP programme.

The selection process for interviews was originally a stratified sample but this transitioned to a snowball strategy which may have resulted in selection and reporting bias and resulting in the same issues being 
raised and interviews reaching saturation point earlier. The interviews, however, continued to elicit a range of both positive and negative comments on a range of topics. There are likely to also be some limitations with the transferability of findings to other groups and organizations as some issues raised may be specific to WHO policies and procedures.

\section{What Is Added To The Literature}

Studies have recognised a dearth of organisational learning when examining the impact of emergency work on humanitarian workers (10). The protracted nature of the humanitarian crisis in Cox's Bazar has enabled this study to be designed and implemented whilst the emergency was ongoing. This allowed interviews to take place with key personnel, with many deployees still available for interview. The engagement of deployees in the evaluation of the response is something that should be done on a more routine basis.

This study has examined the experiences of field workers deployed to a humanitarian emergency response and identified four main areas which contribute to the perceived quality and effectiveness of the deployments which may be considered to improve future deployments. The study has underscored the invaluable role of operational partnerships, early in emergency response, while medium-term oriented planning is being operationalized.

\section{Declarations}

\section{Ethics approval and consent to participate}

The study was undertaken for service evaluation, therefore ethical approval was not required. Informed consent to participate in the interviews was obtained from participants, and they were assured that they were free to withdraw at any point, responses would be kept confidential, and that there would be no repercussions from their participation.

\section{Consent for publication}

There are no identifiable details, images, or videos relating to an individual person. Those participating in interviews were informed that the study was conducted to produce a review of operational partnerships in Cox's Bazar, and that their responses would be used to inform the review.

\section{Availability of data and materials}

The datasets used and/or analysed during the current study are available from the corresponding author on reasonable request. 


\section{Competing interests}

The authors declare that they have no competing interests.

\section{Funding}

Not applicable

\section{Authors' contributions}

RO, AP and EE designed the study and identified initial interviewees. AP, EE and CB designed the interview schedule. SS collated data for the desk review. CB conducted and transcribed interviews. CB performed initial data analysis, with $A P$ and $A B$ refining themes. All authors read and approved the final manuscript.

\section{Acknowledgements}

The authors would like to thank the deployees and WHO personnel who generously offered their time to reflect on the role and their experience of operational partnerships.

\section{References}

1. Health Sector Coordination Team. Rohingya Refugee Crisis in Cox's Bazar, Bangladesh: Health Sector Bulletin 03. Cox's Bazar: Bangladesh; 201826 February 2018.

2. UN Refugee Agency. Convention relating to the status of stateless persons, Article 1 (1954).

3. UN High Commussioner for Refugees. UNHCR Bangladesh Factsheet - March 2016. 2016.

4. Milton AH, Rahman M, Hussain S, Jindal C, Choudhury S, Akter S, et al. Trapped in statelessness: Rohingya refugees in Bangladesh. International journal of environmental research and public health. 2017;14(8):942.

5. Mahmood SS, Wroe E, Fuller A, Leaning J. The Rohingya people of Myanmar: health, human rights, and identity. The Lancet. 2017;389(10081):1841-50.

6. Teng TS, Zalilah M. Nutritional status of Rohingya children in Kuala Lumpur. Malaysian J Med Heal Sci. 2011;7(1):41-9.

7. World Health Organization Regional Office for South-East Asia. Regional Framework on operational partnerships for emergency response. New Delhi: World Health Organization; 2017.

8. Standby Partnership. About the Standby Partnership Network 2020 [Available from: https://www.standbypartnership.org/about].

9. World Health Organization. Global Outbreak Alert and Response Network. 2020 [Available from: https:// extranet.who.int/goarn/]. 
10. Stearns SD. Psychological distress and relief work: who helps the helpers? Refugee Participation Network (RPN)1993. p. 3-8.

11. Bjerneld M, Lindmark G, Diskett P, Garrett MJ. Perceptions of work in humanitarian assistance: interviews with returning Swedish health professionals. Disaster Management \& Response. 2004;2(4):101-8.

12. Braun V, Clarke V. Using thematic analysis in psychology. Qualitative research in psychology. 2006;3(2):77-101.

13. World Health Organization. Emergency Response Framework (2nd edition). 2017 [Available from: https://www.who.int/publications/i/item/9789241512299].

14. Salmani I, Seyedin H, Ardalan A, Farajkhoda T. Conceptual model of managing health care volunteers in disasters: a mixed method study. BMC health services research. 2019;19(1):1-9.

15. Rubin GJ, Harper S, Williams PD, Öström S, Bredbere S, Amlôt R, et al. How to support staff deploying on overseas humanitarian work: a qualitative analysis of responder views about the 2014/15 West African Ebola outbreak. European journal of psychotraumatology. 2016;7(1):30933.

16. Brooks J, Erickson TB, Kayden S, Ruiz R, Wilkinson S, Burkle FM. Responding to chemical weapons violations in Syria: legal, health, and humanitarian recommendations. Conflict and health. 2018;12(1):1-7.

17. Bjerneld M, Lindmark G, McSpadden LA, Garrett MJ. Motivations, concerns, and expectations of Scandinavian health professionals volunteering for humanitarian assignments. Disaster Management \& Response. 2006;4(2):49-58.

18. Blecken A, editor Logistics in the context of humanitarian operations. International Heinz Nixdorf Symposium; 2010: Springer.

19. Cozzolino A. Humanitarian supply chain relationships: Working together to meet the challenge of preparing for and responding to disasters. Humanitarian Logistics: Springer; 2012. p. 17-37.

\section{Figures}




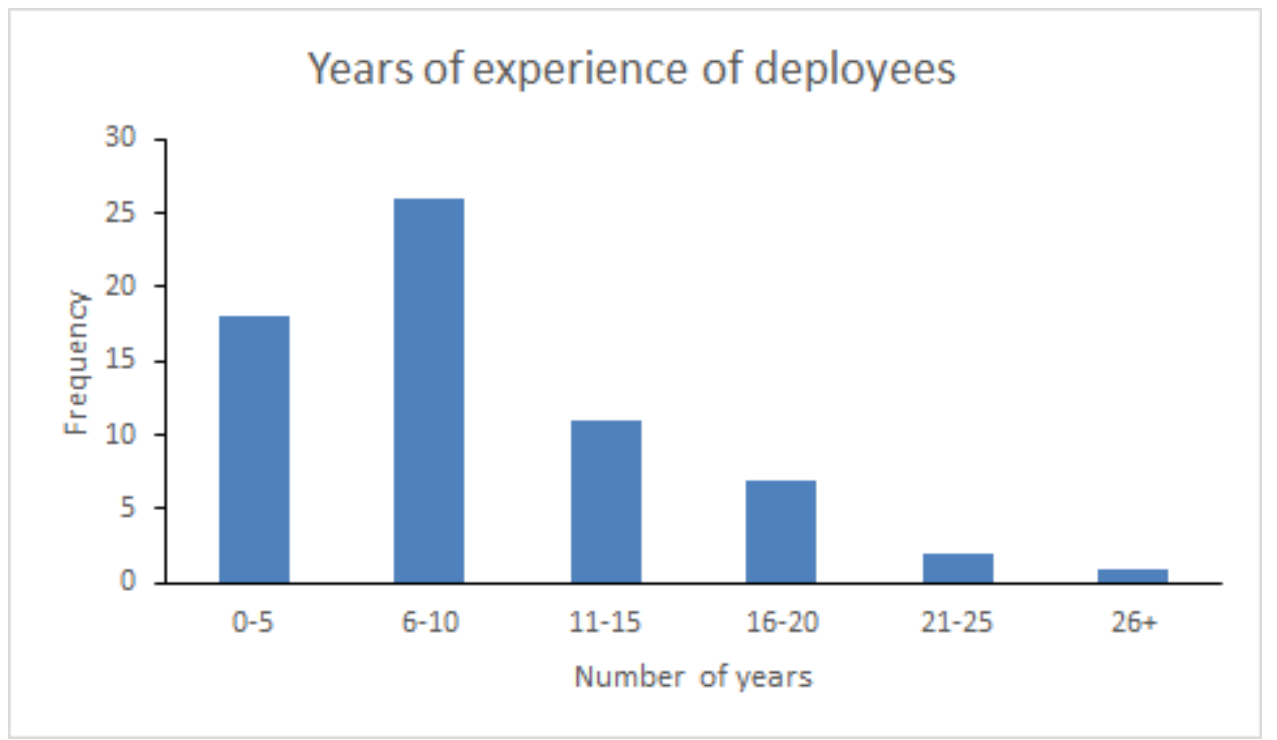

Figure 1

Number of years of relevant occupational experience of personnel deployed to Cox's Bazar

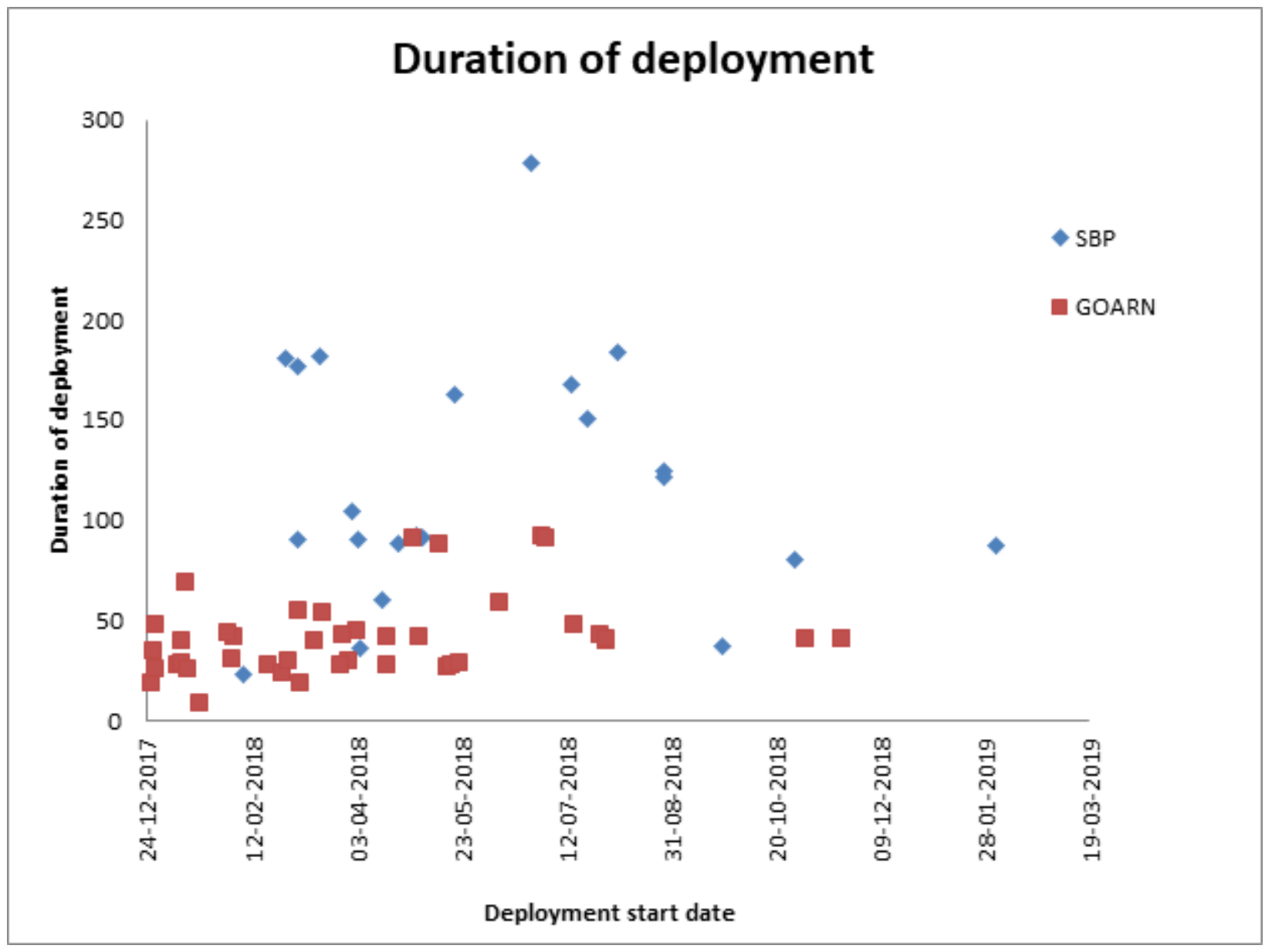

Figure 2

Duration of deployment of deployees within the WHO Cox's Bazar sub-office by deployment mechanism, December 2017 - February 2019 


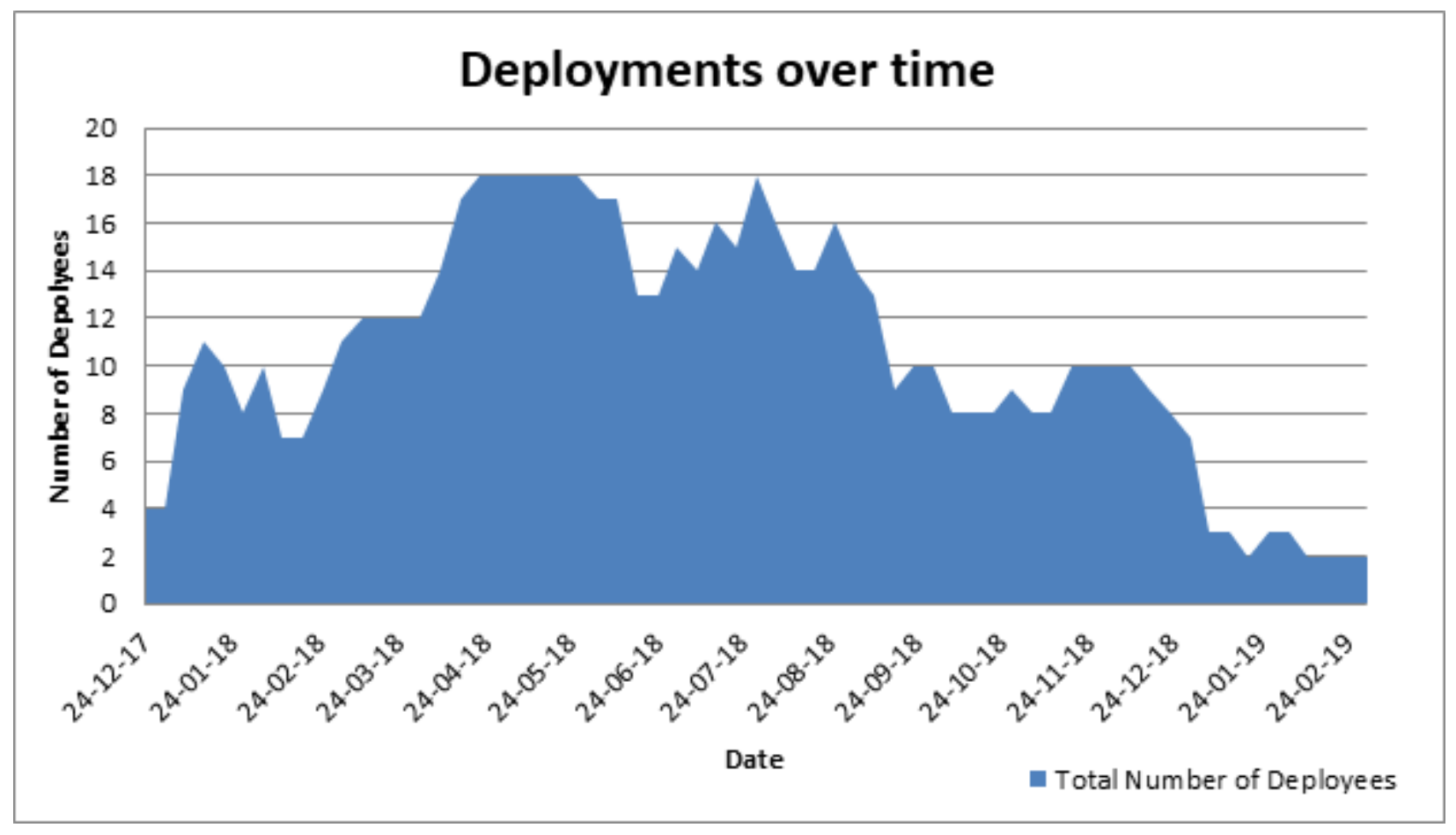

\section{Figure 3}

Number of deployees within the WHO Cox's Bazar sub-office December 2017 - February 2019

\section{Supplementary Files}

This is a list of supplementary files associated with this preprint. Click to download.

- SupplementaryMaterials.docx 